Seed Science Research

cambridge.org/ssr

\section{Research Opinion}

Cite this article: Ellis RH (2019). Temporal patterns of seed quality development, decline, and timing of maximum quality during seed development and maturation. Seed Science Research 29, 135-142. https://doi.org/10.1017/ S0960258519000102

Received: 6 December 2018

Revised: 5 March 2019

Accepted: 7 April 2019

First published online: 12 June 2019

Keywords:

mass maturity; seed development; seed harvest; seed longevity; seed maturity; seed quality

Author for correspondence:

Richard Harold Ellis, Email: r.h.ellis@reading. ac.uk

\title{
Temporal patterns of seed quality development, decline, and timing of maximum quality during seed development and maturation
}

Richard H. Ellis

School of Agriculture, Policy and Development, University of Reading, Earley Gate, PO Box 237, Reading RG6 6AR, UK

\begin{abstract}
The long-standing hypothesis that seed quality improves during seed filling, is greatest at the end of seed filling, and declines thereafter (because seed deterioration was assumed to begin then), provided a template for research in seed quality development. It was rejected by investigations where seed quality was shown to improve throughout both seed development and maturation until harvest maturity, before seed deterioration was first observed. Several other temporal patterns of seed quality development and decline have also been reported. These are portrayed and compared. The assessment suggests that the original hypothesis was too simple, because it combined several component hypotheses: (a) the seed improvement (only) phase ends before seed deterioration (only) commences; (b) there is only a brief single point in time during seed development and maturation when, in all circumstances, seed quality is maximal; (c) the seed quality improvement phase coincides perfectly with seed filling, with deterioration only post-seed filling. It is concluded that the search for the single point of maximum seed quality was a false quest because (a) seed improvement and deterioration may cycle (sequentially if not simultaneously) during seed development and maturation; (b) the relative sensitivity of the rates of improvement and deterioration to environment may differ; (c) the period of maximum quality may be brief or extended. Hence, when maximum quality is first attained, and for how long it is maintained, during seed development and maturation varies with genotype and environment. This is pertinent to quality seed production in current and future climates as it will be affected by climate change and a likelihood of more frequent coincidence of brief periods of extreme temperatures with highly sensitive phases of seed development and maturation. This is a possible tipping point for food security and for ecological diversity.
\end{abstract}

\section{Introduction}

The best time to harvest seeds during their development and maturation is when they attain maximum quality. When is this? And how should seed quality be assessed and quantified to answer this question?

One simple, widely known, attractive (at first acquaintance) answer to the first question was the hypothesis that seed quality improves until physiological maturity (end of the seed-filling phase; Shaw and Loomis, 1950; Box 1) and that thereafter seeds deteriorate because 'nutrients are no longer flowing into the seed from the mother plant' (Harrington, 1972).

The hypothesis has been supported by a wide range of researchers (e.g. Eastin et al., 1973; Benedict et al., 1976; Maguire, 1977; Browne, 1978; Delouche, 1980; Powell et al., 1984; Rasyad et al., 1990; TeKrony and Egli, 1997). The attractiveness of the hypothesis when introduced was, I suggest, twofold. First, the very use of the term physiological maturity made the hypothesis appear irrefutable. Indeed, some of the term's more recent usage has divorced it from the original 1950 definition (Box 1). Secondly, this developmental stage coincides with the termination of assimilate supply to the seeds.

If the hypothesis is correct, then why do seed producers (of most crops) delay harvest until later? Similarly, why are seeds of wild species rarely shed at this developmental stage? Indeed, seeds of Galanthus nivalis L. and Narcissus pseudonarcissus L. are shed early in their development and the embryos continue their development post-shedding in moist conditions with improvement to seed quality (Newton et al., 2013), but this is not common.

Harrington's hypothesis implies that in order to produce seeds of the best quality, producers should harvest seeds whilst their moisture content remains comparatively high, given that the moisture status of seeds at the end of the seed-filling phase approaches that of the mother plant; e.g. 42-49\% moisture content in barley (Hordeum vulgare L.) and wheat (Triticum aestivum L.) (Ellis and Pieta Filho, 1992). This requires great care in handling very moist seeds, particularly in those species where seeds are bruised by mechanical damage at such moisture contents (Moore, 1972), together with considerable drying ex planta. 
Box 1. Phases and stages of seed development

\section{Seed-filling phase}

After anthesis and seed set, there is an initial period of cell division and histodifferentiation as the embryo develops (Black et al., 2006). This appears as a lag phase in the relation between seed dry weight and duration from anthesis, often around 7-10 days, as there is no detectable change in weight. The seed-filling phase then commences with a constant or almost constant gradient until it ends and so can be represented by a straight line relation (e.g. Pieta Filho and Ellis, 1991a). After the end of the seed-filling phase, there is no further change in seed dry weight and this is represented by a plateau (maximum dry weight). Sometimes the beginning and end of seed filling is less abrupt, with a sigmoidal relation between seed dry weight and duration from anthesis (Egli, 1998). In these cases too, the rate of seed filling can still be estimated as a constant (Egli, 1998), with the end of seed filling when $95 \%$ of the asymptotic value is attained.

\section{Physiological maturity}

Physiological maturity is the end of the seed-filling phase (Shaw and Loomis, 1950). Those agronomists introduced that term for this seed developmental stage to highlight that later agronomic interventions could not increase crop seed yield, because the funiculus loses functionality and so dry matter cannot be transferred from the mother plant to the seed. Harrington (1972) cited that definition in his hypothesis that this seed developmental stage is also that at which seed quality is greatest, because seed quality improves during the seed-filling phase but seeds deteriorate thereafter and so seed quality declines. In support of this observation regarding the apparent simultaneous end of seed weight increase and seed quality improvement, Harrington (1972) noted that after physiological maturity 'nutrients are no longer flowing into the seed from the mother plant'.

Perhaps less well recognized, however, was the subsequent comment that 'maximum dry weight may provide an index of physiological maturity, but not always' (Harrington, 1972). This led to some distortion or inconsistent use of the term. For example, physiological maturity was said to occur some days after maximum seed dry weight was attained in two Brassica seed crops (Still and Bradford, 1998), contradicting the definition of Shaw and Loomis (1950). Nor did Black et al. (2006) link their definition directly to the original seed developmental stage. They reduced the definition of physiological maturity from that of Harrington's, to the 'stage of development at which a seed, or the majority of a seed population, has reached its maximum viability and vigour'. Nonetheless (given that the moisture status of seeds at the end of the seed-filling phase is similar to the mother plant), they maintained an indirect link to the earlier definition by adding '... not usually the stage of maturity at which seed should be harvested [...] since seeds generally achieve physiological maturity at moisture contents that are too high .... Finch-Savage and Bassel (2016) also divorced the definition of physiological maturity from the original (end of the seed-filling phase) to define it solely as the point of maximum seed quality. They also noted that this occurs after mass maturity (see below) and usually before harvest maturity (see below).

Egli (1998), on the other hand, re-iterated the original definition of Shaw and Loomis (1950) and suggested that where sigmoidal relations between seed dry weight and duration from anthesis were detected then there were two values for physiological maturity: an estimated value provided by the intercept of the intrinsic linear relations; and an actual estimate when the asymptote was reached. He also noted that, because data are often not collected to calculate physiological maturity accurately, indirect (visual) indicators are often applied - such as the appearance of a black layer in maize (Zea mays L.) seeds (Egli, 1998).

\section{Mass maturity}

Given that the definition of physiological maturity had become compromised and so misleading in seed science, the term mass maturity was proposed to designate the end of the seed-filling phase (Ellis and Pieta Filho, 1992). For the avoidance of doubt, mass maturity is the seed developmental stage that Shaw and Loomis (1950) termed physiological maturity.

\section{Maturation drying}

The moisture content of seeds declines throughout their development and maturation. The decline is caused by the proportionally greater accumulation of assimilate than water (Egli, 1990) during the seed-filling phase. The latter ends at mass maturity and the further decline in seed moisture content - the maturation-drying phase, which ends at harvest maturity - results from net loss in water from seeds. Mass maturity can be estimated by analysing serial results for seed weight and moisture content simultaneously (Pepler et al., 2006). Seeds in fleshy fruits also show net loss in water after mass maturity (e.g. Demir and Ellis, 1992b). Probert et al. (2007) describe this period as the post-abscission phase of seed development.

\section{Harvest maturity}

The term harvest maturity is somewhat imprecise, given that the maturity stage at which a seed crop is harvested varies amongst crops, and within crops amongst different farming systems in different parts of the world. Hence, for example, it is the '... stage of development which is seed or the majority of the seed population is best suited to harvesting in high quality and yield, considering its storage, its handling characteristics to minimise mechanical injury, and potential field losses ...' during harvest (Black et al., 2006). Kelly and George (1998) recognized a diversity of seed harvest practices, but noted 'If panicles are to be sun-dried, the harvest commences at 16 to $18 \%$ moisture'. This outcome is similar to the definition used here: excluding seeds within fleshy fruits, the seed developmental stage of harvest maturity is the end of the seed maturation phase by when seed moisture content has declined to values approaching equilibrium with the ambient environment. In the UK for starchy seed crops such as wheat (Triticum aestivum L.), for example, this is typically 14-16\% moisture content (matching the traditional grain brittleness test - hard, but liable to break easily), but in oily seeds such as oilseed rape (Brassica napus L.) 8-10\% moisture content. 
Perhaps not surprisingly then, other researchers reported that seed quality continues to improve after (Wilson and Trawatha, 1991) or well after physiological maturity sensu stricto (e.g. Kameswara Rao et al., 1991; Pieta Filho and Ellis, 1991a, b; Demir and Ellis, 1992a, b, 1993; Ellis and Pieta Filho, 1992; Ellis et al., 1993; Ellis and Hong, 1994; Zanakis et al., 1994; Hay and Probert, 1995; Sanhewe and Ellis, 1996; Sanhewe et al., 1996; Hay et al., 1997; Sinniah et al., 1998a; Hay et al., 2010; Pereira Lima et al., 2017; Basso et al., 2018), or even later after seeds are shed from mother plants (e.g. Probert et al., 2007; Newton et al., 2013) refuting Harrington's hypothesis. Given these contradictory reports, and so the potential of the use of the term physiological maturity to mislead with regard to seed quality, the term mass maturity was proposed to designate the end of the seed-filling phase (Box 1).

As well as direct evidence to reject the hypothesis, evidence that important maturation events occur within seeds after the vascular connection with the mother plant is lost (Galau et al., 1991; Leprince et al., 2017) repudiated the earlier assumption that ending nutrient supply to seeds at physiological maturity inevitably terminates seed quality improvement. Oligosaccharides and low-molecular weight proteins have each been shown to accumulate within seeds in planta after physiological maturity, with each positively associated with seed quality improvement during seed development and maturation (Sinniah et al., 1998b). Proteins and RNA produced late in seed maturation are important for subsequent seed longevity (Chatelain et al., 2012) and for the successful completion of the seed germination process upon imbibition after storage (Dirk and Downie, 2018).

There are circumstances where seed producers do act comparatively soon after the end of the seed-filling phase. Where seeds vary in maturity date and/or have a high propensity to shatter and shed, for example certain oilseeds or grass seed crops, the crop may be cut well before seeds mature and left as a swath in the field to mature further and to dry. The swath traps the shattered seeds, whilst cutting the whole crop hastens the maturation of lessdeveloped seeds, and all seeds (previously shed or not) are subsequently threshed from the swath. In such cases, maturation drying of seeds occurs within the swath. Seed maturation has been shown to continue ex planta in environments which mimic those in planta, with seed quality improvement and, for example, the accumulation of oligosaccharides continuing ex planta (Hong et al., 2000). Indeed, in some cases the initial environment ex planta may benefit seeds harvested late in seed development and maturation: in rice (Oryza sativa L.) and some other crops, the quality of seeds harvested at high moisture content was improved considerably by high-temperature drying (Whitehouse et al., 2015, 2017, 2018a, b). Evidence from ex planta studies also contradicts Harrington (1972), therefore.

Roberts (1999) discussed his approach to seed science as a search for patterns. Such patterns can provide visual representations of our understanding, or hypotheses. Visual representations of several contrasting patterns of changes in seed quality, improvement and decline, during seed development and maturation are presented here in order to consider, challenge, and summarize advances in our understanding nurtured by Harrington's original, thought-provoking hypothesis.

\section{Temporal patterns of seed quality development and decline for different criteria}

The sensitivity of any particular test to assess seed quality has the potential to modify the extent of any variation detected by that

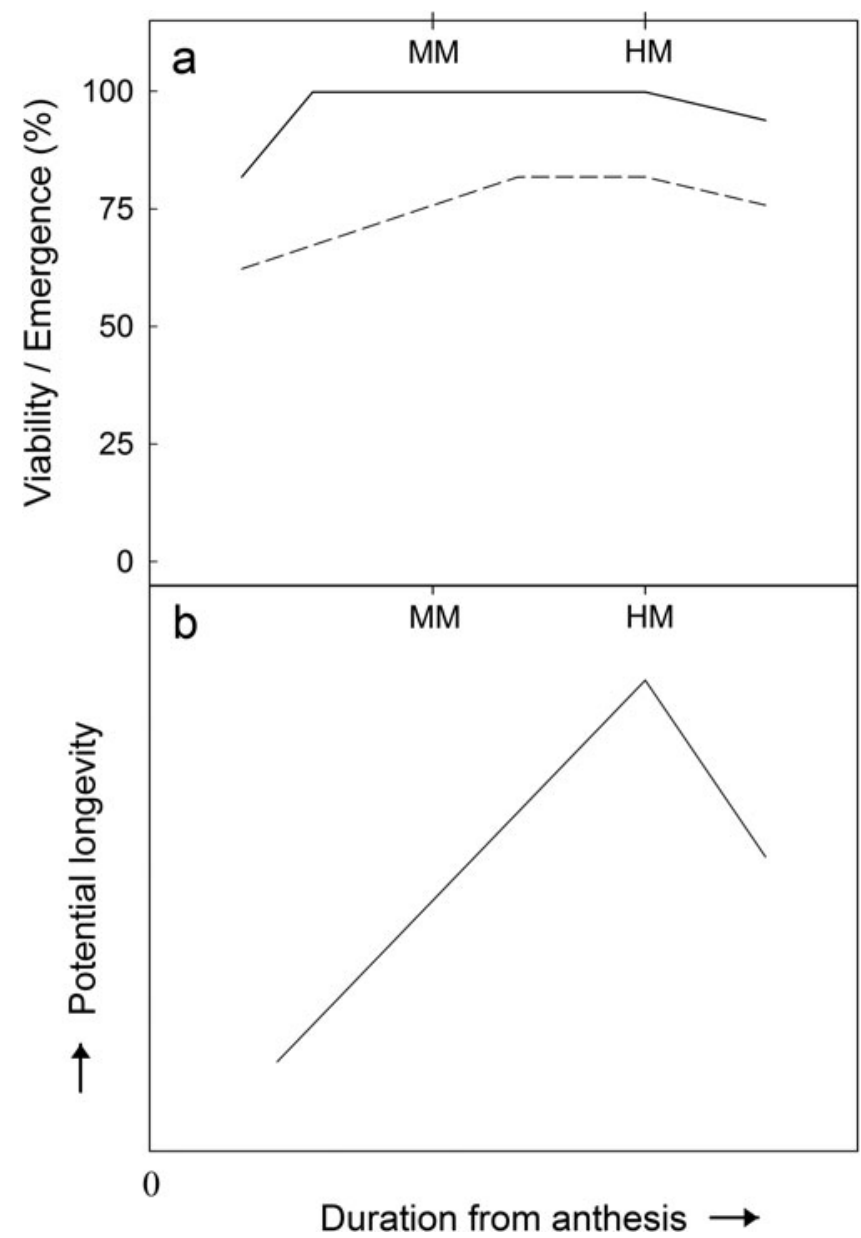

Fig. 1. Comparison of outline temporal patterns of seed quality development and decline during seed development and maturation (duration from anthesis) amongst three different methods of assessing seed quality: ability to germinate in standard laboratory tests (panel a, continuous line); emergence of seedlings from the field seedbed (panel a, dashed line); longevity in air-dry hermetic storage (panel b). These schematic patterns are abridged results for seeds of barley produced in 1988 (Pieta Filho and Ellis, 1991a, b). MM, mass maturity; HM, harvest maturity.

test. Standard germination test environments to determine seed viability are designed to provide optimal conditions for germination, including breaking dormancy (ISTA, 2015). The results of the test have upper and lower boundaries $(100 \%$ and $0 \%$, respectively). Seedling emergence in the field occurs typically in suboptimal environments, but is also constrained by the same numerical boundaries (Fig. 1a). Such data are binary in which one fraction of the seed population is able to germinate whilst the remaining individuals do not. Similarly in the harsher environment of the seedbed a smaller fraction of the seed population is able to produce seedlings. These are examples of populationbased thresholds where the fraction of the population able to pass the threshold is a function of the seedbed environment (Ellis and Roberts, 1981; Finch-Savage and Bassel, 2016; Bradford, 2018). Seed vigour is defined by reference to many variables including seed lot performance in the field (Perry, 1978; ISTA, 2015). At the heart of the concept of seed vigour is the variability amongst seed lots in their ability to produce seedlings the harsher the seedbed environment, as exemplified by the seed-lot-by-environment interaction (Hegarty, 1978). Such interactions can be explained, and quantified, by population-based 
thresholds which consider the progress of deterioration (ageing) in the individual seed and the consequences for the performance of different seed lots (Ellis and Roberts, 1980, 1981; Khah et al., 1986; Ellis and Dolman, 1988). The extent, or absence, of ageing in a seed lot is thus an important aspect of seed quality, sometimes described as physiological quality to distinguish it from variation resulting from mechanical, pest, or disease damage.

Figure 1 provides a stylized, simplified representation of changes in seed quality in barley during seed development and maturation in one year where seed quality was assessed in each of three different ways (Pieta Filho and Ellis, 1991a, b): ability to germinate in standard laboratory tests; field emergence; or longevity in air-dry storage. The upper limit provided by ability to germinate following desiccation and rehydration was reached comparatively early in development and then maintained for a considerable period of subsequent development and maturation in planta (32 days; Pieta Filho and Ellis, 1991a) until harvest maturity in this example (Fig. 1a). Seedbed environments are rarely optimal for germination and seedling emergence. This is shown in Fig. 1a, where the field emergence of seedlings was always less than the ability of seeds to germinate in laboratory germination tests. In addition, the period of seed development and maturation during which field emergence ability was greatest (11 days; Pieta Filho and Ellis, 1991b) was shorter than that for ability to germinate. That is, the more sensitive test of seed quality reduced the apparent period during which seeds, if harvested, showed maximum seed quality.

Seed longevity in air-dry storage is a continuous variable which provides another method of assessing changes in seed quality during seed development and maturation. It provided a pattern where seed quality improved during most of the study period, until maximum quality was attained at harvest maturity, and seed quality declined thereafter (Fig. 1b). Hence, the three different methods of assessment in Fig. 1 provided compatible, but not identical, results: all methods showed a simultaneous decline in quality immediately after harvest maturity, to a greater (longevity) or lesser (laboratory germination and field emergence) extent, after earlier improvement in quality. How early maximum quality was attained varied amongst the different assessment procedures, however: earliest for ability to germinate and latest for longevity. As a consequence, the duration of maximum quality in planta was shorter (longevity < field emergence < laboratory germination) the more sensitive the method of assessment. Hence, assessing seed longevity has considerable utility in investigations of seed quality development.

\section{Variation in temporal patterns of seed quality development and decline}

An inverted $\mathrm{V}$ portrays the temporal pattern of change in seed quality where seed quality improves until the end of the seedfilling phase and then declines as proposed by Harrington (1972). In this representation of his hypothesis, the two trend lines intersect at mass maturity (Box 1) to provide maximum seed quality at that developmental stage (Fig. 2a).

In this and the subsequent stylized outline temporal patterns, the angle $\alpha$ indicates that the gradient of improvement or decline in seed quality over developmental time is affected by the seed production environment. For example, in wheat the former is a function of temperature (Sanhewe et al., 1996). In addition, as the angle is a function of environment, it may change during seed quality improvement and/or decline as the seed production environment varies from day to day. For example, in barley there was almost a pause (i.e. $\alpha$ tended to zero) in seed quality improvement for a short period in one year (Pieta Filho and Ellis, 1991a).

Pieta Filho and Ellis (1991a) presented results for changes in barley seed longevity during seed development and maturation in 1988 which approximated to an inverted V, but where maximum seed quality coincided with harvest maturity (Fig. 2b). The weather during seed development and maturation in the following year, 1989, was warmer and drier (Pieta Filho and Ellis, 1991a). In that year also, barley seed longevity showed a consistent improvement until harvest maturity, but in contrast to the previous year the subsequent decline was delayed for 10-15 days and so the inverted-V temporal pattern was modified with a brief plateau at the peak (Fig. 2c). In tomato (Solanum lycopersicum), this plateau of maximum seed quality was of considerable duration, at least 40 days (Demir and Ellis, 1992b).

In similar research with several contrasting cultivars of each of barley and wheat, the results showed consistently that seed longevity continued to improve long after mass maturity (Ellis and Pieta Filho, 1992). In some cultivars the improvement continued until harvest maturity, and so matched the patterns in Fig. $2 \mathrm{~b}$ and $2 c$. In others, however, maximum longevity was attained slightly earlier and so before harvest maturity (Fig. 2d). Similarly, results for different cultivars of soyabean (Glycine max L.) in two seasons matched the temporal pattern in either Fig. $2 \mathrm{c}$ or $2 \mathrm{~d}$ (Zanakis et al., 1994).

Contrasting cultivars of rice in one temperature regime showed similar patterns where seed longevity continued to improve for about 20 days after mass maturity reaching maximum values shortly before harvest maturity (Ellis et al., 1993), matching the temporal pattern in Fig. 2d. This was also the case for Indica and Javanica rice cultivars in a much warmer regime, whereas a Japonica cultivar failed to show further improvement in longevity from close to mass maturity onwards in that warmer regime. This genotype-by-environment interaction resulted in poor longevity in that case, but that poor value was maintained in planta for the subsequent 20-30 days before deterioration began to be detected (Fig. 2e). Note that in this particular genotype-environment combination, the Harrington hypothesis was met in one part: net seed quality improvement was limited to the seed-filling phase; but decline in seed quality in planta did not then commence.

The final temporal pattern presented (Fig. 2f) summarizes results from a 5-year investigation on the consequences of rainfall events for seed quality development in wheat. Rainfall events during seed development and maturation damaged seed quality immediately, but the damage was reversed after a short further period in planta during which seeds (re)dried (Ellis and Yadav, 2016; Yadav and Ellis, 2016). That effect was repeatable under successive rainfall events. Moreover, the effect was identified in planta in three phases of seed development and maturation: before mass maturity; between mass maturity and harvest maturity; and after harvest maturity. Hence, the trends of seed quality improvement and those of seed deterioration in Fig. 2 each represents net changes in seed quality: improvement and deterioration processes are both possible within each phase (Yadav and Ellis, 2016).

Villiers and Edgcumbe (1975) showed that repeated deterioration and improvement in seed quality occur ex planta also. They introduced the repair hypothesis to explain the improvement part of the cycle. Provided oxygen is available and 


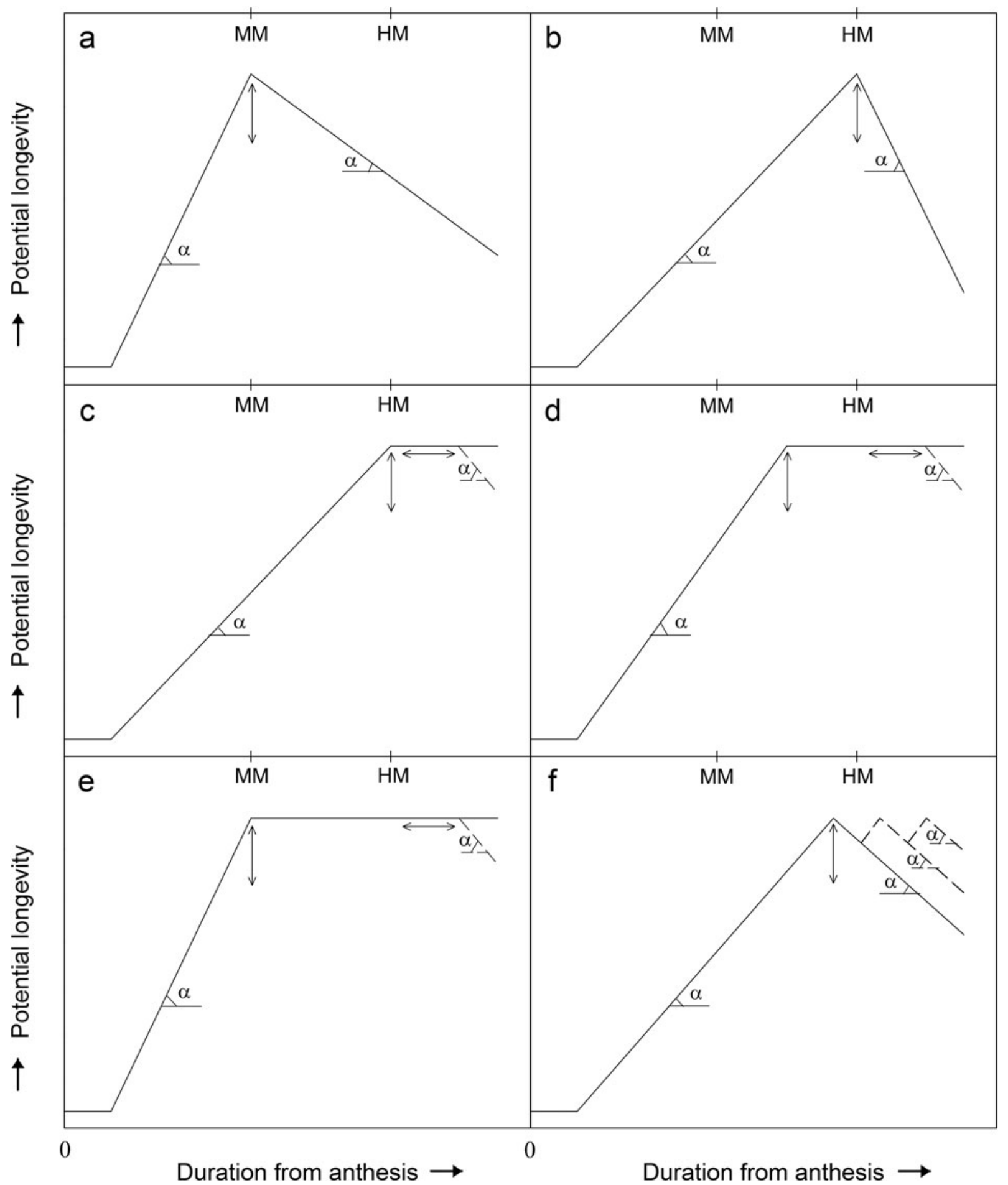

Fig. 2. Contrasting outline temporal patterns of seed quality (assessed by longevity in subsequent air-dry hermetic storage) development and decline during seed development and maturation (duration from anthesis) reported by various authors for different seed crops in different environments in planta: MM, mass maturity; $\mathrm{HM}$, harvest maturity; $\alpha$ is the (variable) angle of change in seed quality (rate of increase or decrease in seed quality); vertical bidirectional arrows indicate that the value of maximum seed quality varies with environment and genotype; dashed lines of negative slope indicate decline in seed quality which begins after a variable duration of the maintenance of maximum seed quality; horizontal bidirectional arrows indicate that the timing of when such a decline may be observed varies with environment and genotype. Pattern (a) represents the hypothesis that seed quality improves during seed development and maturation until the end of the seedfilling phase and declines thereafter (Harrington, 1972); (b) that reported for the longevity of barley seeds produced in 1988 (Pieta Filho and Ellis, 1991 a) where seed quality improved throughout seed development and maturation until harvest maturity, and then declined; (c) that reported for the longevity of barley seeds produced in 1989 (Pieta Filho and Ellis, 1991a) where high seed quality was maintained after the peak was first achieved; (d) that reported for the longevity of barley and wheat seeds produced in 1988 or 1989 (Pieta Filho and Ellis, 1991a) where several cultivars reached peak quality during maturation drying and before harvest maturity and maintained their quality until harvest maturity or later; (e) that reported for Japonica rice in a comparatively hot environment where improvement in seed quality ended close to mass maturity with little further change in quality during maturation drying (Ellis et al., 1993); (f) that reported for reported for wheat seeds subjected to rainfall and drying cycles where damage to seed quality from rainfall was reversed after drying in planta (Yadav and Ellis, 2016). 
germination is prevented (by dormancy), seed longevity ex planta can be considerable in very moist seeds (Ibrahim and Roberts, 1983; Ibrahim et al., 1983). High humidity or priming (Heydecker and Gibbins, 1978) at harvest may also improve seed longevity in some circumstances (Powell et al., 2000; Butler et al., 2009), but is detrimental in other circumstances (Argerich et al., 1989; Tarquis and Bradford, 1992). Priming in early maturation (soon after mass maturity) did improve air-dry longevity in pepper (Capsicum annuum L.) but only acted to hasten seed improvement because priming later in seed development and maturation reduced longevity (Demir and Ellis, 1992a).

\section{Discussion}

These diverse temporal patterns of seed quality development and decline (Fig. 2) refute the hypothesis that seed quality is always greatest at mass maturity and then declines (Fig. 2a). A simple amendment of the original hypothesis to one where seed quality is instead greatest at harvest maturity before then declining (Fig. 2b) must also be rejected: it does occur, but there are further different temporal patterns of seed quality development and decline (Fig. 2).

The original hypothesis (Harrington, 1972) was a conceptual framework. It consisted of several discrete hypotheses: (a) a phase of seed improvement which ends before seed deterioration then begins; (b) one single point during seed development and maturation, in all circumstances, when seed quality is maximal; (c) improvement in seed quality coincides temporally with seed filling perfectly; (d) deterioration always, and only, occurs postseed filling; and hence, seed quality is maximal at the end of the seed-filling phase and then declines.

An improved conceptual framework would, I suggest, consist of the following: (a) seed improvement and deterioration processes can each cycle during seed development and maturation (Yadav and Ellis, 2016), cycling sequentially if not simultaneously; (b) the relative sensitivity of rates of improvement and deterioration to environment (including seed moisture status) may differ, and this relativity may alter as seed development and maturation progress. For example, warmer temperatures in early seed development damage whereas warmer temperatures in late seed maturation benefit subsequent seed quality in wheat (Nasehzadeh and Ellis, 2017); and developing rice seeds were most vulnerable to damage from high (and also low) temperature in the 7 or 14 days after anthesis (Martínez-Eixarch and Ellis, 2015), but their longevity was improved by high-temperature drying in late maturation in contrast (Whitehouse et al., 2018a).

As a consequence, as experimenters we estimate the net consequence of gross improvement and deterioration from assessments at any one seed developmental stage. Hence, the various plateaus (no change in seed quality over a particular duration in planta) shown in Fig. $2 c-e$ represent periods where the rate of improvement more or less equals the rate of deterioration. Similarly the triple peaks in Fig. $2 \mathrm{f}$ provide a stable saw-tooth regulator effect: smoothing out observations over several days would give an impression of no change in seed quality. These considerations match the repair hypothesis of Villiers and Edgcumbe (1975) for the post-harvest survival of seeds in aerated environments that are continuously or regularly at high moisture contents.

It follows that the period that maximum seed quality is maintained in planta can be extended in some seed production environments beyond just a brief period of 'peak' quality. In addition, precisely when maximum quality is attained during seed development and maturation can vary depending upon environment, considerably in the case of the Japonica rice example (Ellis et al., 1993). That is, the genotype-by-environment interaction affects three important facets: the value of maximum seed quality; when it is first attained during seed development and maturation; and for how long it is maintained thereafter in planta.

These observations are relevant to investigations of the effect of environment on quality seed production; to the production of high-quality seeds; and to the breeding and selection of improved cultivars with better quality seed production. They are, moreover, pertinent to understanding the potential impacts of climate change on the production of quality seeds, especially in more marginal crop (and seed) production areas and with regard to the effects of brief episodes of extreme temperature, and to work to maximize the positive effects (e.g. cereal seed production at high latitudes; Sanhewe et al., 1996) and mitigate the negative effects (e.g. rice seed production at risk of flooding: Tejakhod and Ellis, 2018) of climate change. In particular, increase in temperature has the potential to alter the temporal pattern of change in seed quality from that shown in Figure $2 \mathrm{c}$ towards that in Figure 2e, with consequent severe reduction in seed quality (Ellis et al., 1993; Ellis and Hong, 1994), an agribotanical-environmental tipping point of considerable possible severity for food security and ecological diversity alike.

Author ORCIDs. (D) Richard H. Ellis, 0000-0002-3695-6894

Acknowledgements. I thank all my past collaborators for their many contributions to this topic and Dr James Ryalls for help preparing the figures.

\section{References}

Argerich CA, Bradford KJ and Tarquis AM (1989) The effects of priming and ageing on resistance to deterioration of tomato seeds. Journal of Experimental Botany 40, 593-598.

Basso DP, Hoshino-Bezerra AA, Sartori MMP, Buitink J, Leprince $O$ and da Silva EAA (2018) Late seed maturation improves the preservation of seedling emergence during storage in soybean. Journal of Seed Science 40, 185-192.

Benedict CR, Kohel RJ and Schubert AM (1976) Transport of ${ }^{14} \mathrm{C}$ assimilate to cottonseed: integrity of funiculus during seed filling stage. Crop Science 16, 23-27.

Black M, Bewley JD and Halmer P (2006) The Encyclopaedia of Seeds: Science, Technology and Uses. Wallingford, UK: CABI.

Bradford KJ (2018) Interpreting biological variation: seeds, populations and sensitivity thresholds. Seed Science Research 28, 158-167.

Browne CL (1978) Identification of physiological maturity in sunflower (Helianthus annuus). Australian Journal of Agriculture and Animal Husbandry 18, 282-286.

Butler LH, Hay FR, Ellis RH, Smith RD and Murray TB (2009) Priming and re-drying improve the survival of mature seeds of Digitalis purpurea during storage. Annals of Botany 103, 1261-1270.

Chatelain E, Hundertmark M., Leprince O, Gall SL, Satour P, Deligny-Penninck S, Rogniaux H and Buitink J (2012) Temporal profiling of the heat-stable proteome during late maturation of Medicago truncatula seeds identifies a restricted subset of late embryogenesis abundant proteins associated with longevity. Plant, Cell and Environment 35, 1440-1455.

Delouche JC (1980) Environment effects on seed development in seed quality. HortScience 15, 775-780.

Demir I and Ellis RH (1992a) Development of pepper (Capsicum annuum) seed quality. Annals of Applied Biology 121, 385-399.

Demir I and Ellis RH (1992b) Changes in seed quality during seed development and maturation in tomato. Seed Science Research 2, 81-87. 
Demir I and Ellis RH (1993) Changes in potential seed longevity and seedling growth during seed development and maturation in marrow. Seed Science Research 3, 247-257.

Dirk LMA and Downie AB (2018). An examination of Job's rule: protection and repair of the proteins of the translational apparatus in seeds. Seed Science Research 28, 168-181.

Eastin JD, Hultquist JH and Sullivan GY (1973) Physiological maturity in grain sorghum. Crop Science 13, 175-178.

Egli DB (1990) Seed water relations and the regulation of the duration of seed growth in soybean. Journal of Experimental Botany 41, 243-248.

Egli DB (1998) Seed Biology and the Yield of Grain Crops. Wallingford, UK: CABI.

Ellis RH and Dolman GF (1988) The germination and emergence of seeds of winter oilseed rape stored and sown in admixture with pelleted methiocarb. Annals of Applied Biology 112, 555-561.

Ellis RH and Hong TD (1994) Desiccation tolerance and potential longevity of developing seeds of rice (Oryza sativa L.). Annals of Botany 73, 501-506.

Ellis RH, Hong TD and Jackson MJ (1993) Seed production environment, time of harvest and the potential longevity of seeds of three cultivars of rice (Oryza sativa L.). Annals of Botany 72, 583-590.

Ellis RH and Pieta Filho C (1992) The development of seed quality in spring and winter cultivars of barley and wheat. Seed Science Research 2, 9-15.

Ellis RH and Roberts EH (1980) Towards a rational basis for testing seed quality, pp. 605-635 in Hebblethwaite PD (ed), Seed Production. London, UK: Butterworths.

Ellis RH and Roberts EH (1981) The quantification of ageing and survival in orthodox seeds. Seed Science \& Technology 9, 373-409.

Ellis RH and Yadav G (2016) Effect of simulated rainfall during wheat seed development and maturation on subsequent seed longevity is reversible. Seed Science Research 26, 67-76.

Finch-Savage WE and Bassel GW (2016) Seed vigour and crop establishment: extending performance beyond adaptation. Journal of Experimental Botany 67, 567-591.

Galau GA, Jakobsen KS and Hughes DW (1991) The controls of late dicot embryogenesis and early germination. Physiologia Plantarum 81, 280-288.

Harrington JF (1972) Seed storage and longevity, pp. 145-245 in Kozlowski TT (ed), Seed Biology, Vol. III. New York, USA: Academic Press.

Hay FR and Probert RJ (1995) Seed maturity and the effects of different drying conditions on desiccation tolerance and seed longevity in foxglove (Digitalis purpurea L.) Annals of Botany 76, 639-647.

Hay FR, Probert RJ and Smith RD (1997) The effect of maturity on the moisture relations of seed longevity in foxglove (Digitalis purpurea L.). Seed Science Research 7, 341-350.

Hay FR, Smith RD, Ellis RH and Butler LH (2010) Developmental changes in the germinability, desiccation tolerance, hardseededness, and longevity of individual seeds of Trifolium ambiguum. Annals of Botany 105, 1035-1052.

Hegarty TW (1978) Seed and soil factors affecting the level and rate of emergence. Acta Horticulturae 72, 11-25.

Heydecker W and Gibbins BM (1978) The 'priming' of seeds. Acta Horticulturae 83, 213-224.

Hong TD, Gedebo A and Ellis RH (2000) Accumulation of sugars during the onset and development of desiccation tolerance in immature seeds of Norway maple (Acer platanoides L.) stored moist. Seed Science Research 10, $147-152$.

Ibrahim AE and Roberts EH (1983) Viability of lettuce seeds. 1. Survival in hermetic storage. Journal of Experimental Botany 34, 620-630.

Ibrahim AE, Roberts EH and Murdoch AJ (1983) Viability of lettuce seeds. 2. Survival and oxygen-uptake in osmotically controlled storage. Journal of Experimental Botany 34, 631-640.

ISTA (2015) International Rules for Seed Testing. Bassersdorf, Switzerland: International Seed Testing Association.

Kameswara Rao N, Appa Rao S, Mengesha MH and Ellis RH (1991) Longevity of pearl millet (Pennisetum glaucum) seeds harvested at different stages of maturity. Annals of Applied Biology 119, 97-103.

Kelly AF and George RAT (1998) Encyclopaedia of Seed Production of World Crops. Chichester, UK: Wiley.
Khah EM, Ellis RH and Roberts EH (1986) Effects of laboratory germination, soil temperature and moisture content on the emergence of spring wheat. Journal of Agricultural Science, Cambridge 107, 431-438.

Leprince O, Pellizzaro A, Berriri S and Buitink J (2017) Late seed maturation: drying without dying. Journal of Experimental Botany 68, $827-841$.

Maguire JD (1977) Seed quality and germination, pp. 219-235 in Khan AA (ed), Physiology and Biochemistry of Seed Dormancy and Germination. Amsterdam, Netherlands: North Holland Publishing Company.

Martínez-Eixarch M and Ellis RH (2015) Temporal sensitivity of rice seed development from spikelet fertility to viable mature seed to extremetemperature. Crop Science 55, 354-364.

Moore RP (1972) Effects of mechanical injuries on viability, pp. 94-113 in Roberts EH (ed), Viability of Seeds. London, UK: Chapman and Hall.

Nasehzadeh M and Ellis RH (2017) Seed development and maturation in early spring-flowering Galanthus nivalis and Narcissus pseudonarcissus continues post-shedding with little evidence of maturation in planta. Annals of Botany 120, 479-493.

Newton RJ, Hay FR and Ellis RH (2013) Seed development and maturation in early spring-flowering Galanthus nivalis and Narcissus pseudonarcissus continues post-shedding with little evidence of maturation in planta Annals of Botany 111, 945-955.

Pepler S, Gooding MJ and Ellis RH (2006) Modelling simultaneously water content and dry matter dynamics of wheat grains. Field Crops Research 95, 49-63.

Pereira Lima JJ, Buitink J, Lalanne D, Rossi RF, Pelletier S, da Silva EAA and Leprince $\mathbf{O}$ (2017) Molecular characterization of the acquisition of longevity during seed maturation in soybean. PLoS ONE 12, e0180282. doi.org/ 10.1371/journal.pone.0180282

Perry DA (1978) Report of the vigour test committee 1974-1977. Seed Science and Technology 6, 159-181.

Pieta Filho C and Ellis RH (1991a) The development of seed quality in spring barley in four environments. I. Germination and longevity. Seed Science Research 1, 163-177.

Pieta Filho C and Ellis RH (1991b) The development of seed quality in spring barley in four environments. II. Field emergence and seedling size. Seed Science Research 1, 179-185.

Powell AA, Matthews S and Oliveira M. De A. (1984) Seed quality in grain legumes. Advances in Applied Biology 10, 217-285.

Powell AA, Yule LJ, Jing H.-C., Groot SPC, Bino RJ and Pritchard HW (2000) The influence of aerated hydration seed treatment on seed longevity as assessed by the viability equations. Journal of Experimental Botany 51, 2031-2043.

Probert RJ, Adams J, Coneybeer J, Crawford A and Hay FR (2007) Seed quality for conservation is critically affected by pre-storage factors. Australian Journal of Botany 55, 326-335.

Rasyad DA, Van Sanford DA and TeKrony DM (1990) Changes in seed viability and vigour during wheat seed maturation. Seed Science and Technology 18, 259-267.

Roberts EH (1999) A search for pattern and form. Seed Science Research 9, 181-208.

Sanhewe AJ and Ellis RH (1996) Seed development and maturation in Phaseolus vulgaris. II. Post-harvest longevity in air-dry storage. Journal of Experimental Botany 47, 959-965.

Sanhewe AJ, Ellis RH, Hong TD, Wheeler TR, Batts GR, Hadley P and Morison JIL (1996) The effect of temperature and $\mathrm{CO}_{2}$ on seed quality development in wheat (Triticum aestivum L.). Journal of Experimental Botany 47, 631-637.

Shaw RH and Loomis WE (1950) Bases for the prediction of corn yields. Plant Physiology 25, 225-244.

Sinniah UR, Ellis RH and John P (1998a) Irrigation and seed quality development in rapid-cycling brassica: seed germination and longevity. Annals of Botany 82, 309-314.

Sinniah UR, Ellis RH and John P (1998b) Irrigation and seed quality development in seed quality development in rapid-cycling Brassica: soluble carbohydrates and heat-stable proteins. Annals of Botany 82, 647-655. 
Still DW and Bradford KJ (1998) Using hydro time and ABA-time models to quantify seed quality of Brassicas during development. Journal of the American Society of Horticultural Science 123, 692-699.

Tarquis AM and Bradford KJ (1992) Prehydration and priming treatments that advance germination also increase the rate of deterioration of lettuce seed. Journal of Experimental Botany 43, 307-317.

Tejakhod S and Ellis RH (2018) Effect of simulated flooding during rice seed development and maturation on subsequent seed quality. Seed Science Research 28, 72-81.

TeKrony TM and Egli DB (1997) Accumulation of seed vigour during development and maturation, pp. 369-384 in Ellis RH, Black M, Murdoch AJ and Hong TD (eds), Basic and Applied Aspects of Seed Biology. Proceedings of the Fifth International Workshop on Seeds, Reading, 1995. Dordrecht, Kluwer Academic Publishers.

Villiers TA and Edgcumbe DJ (1975) On the cause of seed deterioration in dry storage. Seed Science and Technology 3, 761-774.

Whitehouse KJ, Hay FR and Ellis RH (2015) Increases in the longevity of desiccation-phase developing rice seeds: Response to high-temperature drying depends on harvest moisture content. Annals of Botany 116, 245-259.
Whitehouse KJ, Hay FR and Ellis RH (2017) High-temperature stress during drying improves subsequent rice (Oryza sativa L.) seed longevity. Seed Science Research 27, 281-291.

Whitehouse KJ, Hay FR and Ellis RH (2018a) Improvement in rice seed storage longevity from high-temperature drying is a consistent positive function of harvest moisture content above a critical value. Seed Science Research 28, 332-339.

Whitehouse KJ, Owoborode OF, Adebayo OO, Oyatomi OA, Olaniyan AB, Abberton MT and Hay FR (2018b) Further evidence that the genebank standards for drying orthodox seeds may not be optimal for subsequent seed longevity. Biopreservation and Biobanking 16, 327-336.

Wilson DO and Trawatha SE (1991) Physiological maturity and vigour in production of Florida Staysweet shrunken-2 sweetcorn. Crop Science 31, $1640-1647$.

Yadav G and Ellis RH (2016) Development of ability to germinate and of longevity in air-dry storage in wheat seed crops subjected to rain shelter or simulated supplementary rainfall. Seed Science Research 26, 332-341.

Zanakis GN, Ellis RH and Summerfield RJ (1994) Seed quality in relation to seed development and maturation in three genotypes of soyabean (Glycine max). Experimental Agriculture 30, 139-156. 